\title{
Dietary diversification for prevention of anaemia among women of childbearing age from rural India
}

\author{
Shobha Rao*, Smita Joshi, Pradnya Bhide, Bhairavi Puranik and Kanade Asawari \\ Biometry \& Nutrition Unit, Agharkar Research Institute, GG Agarkar Road, Pune 411030 , India
}

Submitted 3 July 2012: Final revision received 1 March 2013: Accepted 7 March 2013: First published online 18 April 2013

\begin{abstract}
Objective: To assess the impact of an intervention modifying dietary habits for the prevention of anaemia in rural India.

Design: Intervention study with data on anthropometric (weight, height) measurements, $\mathrm{Hb}$ and diet pattern. As per the cut-off for $\mathrm{Hb}$ in the government programme, women with $\mathrm{Hb}<11 \mathrm{~g} / \mathrm{dl}$ had to be given Fe tablets and formed the supplemented group while those with $\mathrm{Hb}>11 \mathrm{~g} / \mathrm{dl}$ formed the non-supplemented group.

Settings: Three villages near Pune city, Maharashtra, India.

Subjects: Rural non-pregnant women ( $n$ 317) of childbearing age (15-35 years).

Results: After 1 year of intervention, mean $\mathrm{Hb}$ increased (from 10.94 (sD 1.22) g/dl to

11.59 (SD 1.11) $\mathrm{g} / \mathrm{dl})$ significantly $(P<0 \cdot 01)$ with a consequent reduction in the prevalence of anaemia (from $82 \cdot 0 \%$ to $55 \cdot 4 \%$ ) as well as Fe-deficiency anaemia (from $30.3 \%$ to $10 \cdot 8 \%$ ). Gain in $\mathrm{Hb}$ was inversely associated with the initial level of $\mathrm{Hb}$. Significant gain in $\mathrm{Hb}(0.57 \mathrm{~g} / \mathrm{dl})$ was observed among women attending $>50 \%$ of the meetings or repeating $>50 \%$ of the recipes at home $(0.45 \mathrm{~g} / \mathrm{dl})$ in the non-supplemented group and was smaller than that observed in the supplemented group. Consumption of green leafy vegetables more than twice weekly increased substantially from $44 \cdot 7 \%$ to $60 \cdot 6 \%$, as did consumption of seasonal fruits. Logistic regression showed that women with lower participation in the intervention had three times higher risk $(\mathrm{OR}=3 \cdot 08 ; 95 \% \mathrm{CI} 1 \cdot 04,9 \cdot 13 ; P=0 \cdot 04)$ for no gain in $\mathrm{Hb}$ compared with those having high participation.

Conclusions: Developing action programmes for improving nutritional awareness to enhance the consumption of Fe-rich foods has great potential for preventing anaemia in rural India.
\end{abstract}

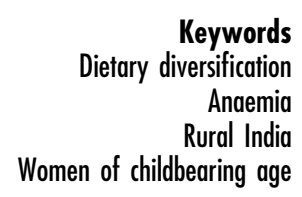

Fe-deficiency anaemia is a common nutritional problem, particularly for women of reproductive age in developing countries. Fe deficiency continues to be the leading single nutrient deficiency in the world, affecting more than two billion persons despite considerable efforts to decrease its prevalence over the past three decades ${ }^{(1)}$. In India, its prevalence in women has been reported to be in the range of 33 to $89 \%$ in different studies ${ }^{(2-8)}$ covering pregnant or non-pregnant women of childbearing age. Although the National Nutritional Anaemia Prophylaxis Program has been in operation since 1970, under which Fe + folic acid tablets are distributed to pregnant women, the evaluation of the programme conducted during 1985-86 showed no impact on the prevalence of anaemia ${ }^{(4)}$.

In practice, the efficiency of large-scale programmes has been limited for various reasons such as poor access to prenatal care, insufficient and inconsistent supply of Fe supplements, insufficient counselling on the need for and the benefits of Fe supplements and an unwillingness by pregnant women to take Fe supplements ${ }^{(9)}$. Besides, malarial infections and worm infestations, known factors associated with anaemia, are commonly prevalent in rural areas. Nevertheless, the importance of dietary deficiencies cannot be overlooked as Fe-deficiency anaemia resulting from inadequate intake and low absorption of dietary Fe has been shown to be the most common cause of anaemia in India ${ }^{(9,10)}$.

The public health approach of Fe fortification of food has had success in the USA in reducing the prevalence of anaemia in women of reproductive age ${ }^{(11)}$, but such approaches - although feasible in developed countries are impractical in economically poor countries. Therefore, an alternative to supplementation is to increase the consumption of micronutrient-rich foods. In a study from rural central Mexico it was reported that better Fe status was associated with higher intakes of non-haem $\mathrm{Fe}$ and foods that contain ascorbic acid ${ }^{(12)}$. Similarly, in Indonesia social marketing played a critical role in increasing the consumption of vitamin A from plant and animal sources ${ }^{(13)}$. Moreover, single micronutrient deficiencies are rare and it is likely that Fe deficiency in anaemic individuals is compounded by multiple micronutrient deficiencies ${ }^{(14)}$. 
Thus, a multi-pronged dietary strategy using a feasible educational programme combined with identifying and promoting the best choices of Fe-rich foods is required to increase the consumption of animal sources of Fe and of vegetables with Fe-absorption enhancers such as vitamin $C^{(15)}$. More research is urgently needed to evaluate dietary approaches, especially those using vegetables for combating Fe deficiency in vegetarian populations. The present study aimed to examine the impact of dietary diversification attempted through live demonstrations of Fe-rich recipes for improving the dietary Fe status of nonpregnant women of childbearing age from rural India.

\section{Materials and methods}

Three villages (Dhamari, Hivare and Pimple), situated within $45 \mathrm{~km}$ from Pune district, Maharashtra, India, were considered for the study. The villages represented the typical Indian village and were largely homogeneous. For the present interventional study, a census was done on all houses in these villages to get a list of eligible women from each house and the women were enrolled in the study only after their oral consent. The census covered a total population of 8300 individuals and the initial number of eligible (15-35 years) non-pregnant women was 317. Most women were from a subsistence farming community with marginal land holdings and were residing in an extended family with their in-laws. Here, we present the data on non-pregnant women from the first year of the study.

\section{Personal information}

Each woman enrolled in the study was interviewed by a nutritionist in a house-to-house visit, using a field-tested structured questionnaire for getting personal information, measuring anthropometric variables and obtaining obstetric history. Personal information comprised the woman's current age, age at menarche, age at marriage, education, type of income-generating work, if engaged in any work other than household work, etc. The woman's weight was measured (to the nearest $200 \mathrm{~g}$ ) using a portable digital weighing balance (ATCO, India) and her height was measured (to the nearest $0 \cdot 1 \mathrm{~cm}$ ) using a stadiometer.

\section{Dietary assessment}

An FFQ, developed in an earlier study ${ }^{(16)}$ for rural mothers from villages in the same area, was used for assessing each woman's habitual dietary pattern. Nevertheless, the FFQ was field-tested before using in the present study but no changes were required. During follow-up, the FFQ was repeated every 6 months.

\section{Hb estimation}

A trained technician accompanying the research team drew a venous blood sample $(2 \mathrm{ml})$ from each woman into an EDTA tube; the tubes were transported to a pathological laboratory in Pune, taking proper precautions. The samples were immediately analysed for $\mathrm{Hb}$ by the cyanmethaemoglobin method and peripheral smear examinations (i.e. colour, size and shape) were conducted. A blood smear was prepared, stained with Leishman stain and covered for $2 \mathrm{~min}$. Then alkaline buffer solution was added and was kept for $10 \mathrm{~min}$. The smear was washed with running distilled water, dried and observed under a microscope to classify nutritional and Fe-deficiency anaemia ${ }^{(17)}$. Normocytic normochromic cells were considered as normal, while normocytic hypochromic with the presence of macrocytic cells was considered as nutritional anaemia indicative of vitamin deficiency. Additionally, hypochromic normocytic with anisocytosis was also considered as nutritional anaemia. Only hypochromic microcytic with anisocytosis/pikilocytosis was considered indicative of Fe-deficiency anaemia. Peripheral blood examination also checked for the presence of malarial parasites.

\section{Composition of research team and their roles}

The research team, comprising a lady doctor, two nutritionists and a technician, visited each of the study villages once per fortnight. The role of the lady doctor was to conduct informal meetings for imparting health-related information, while the nutritionist talked about nutrition-related issues. The nutritionist was also responsible for developing and standardising Fe-rich recipes from locally available green leafy vegetables (GLV) at the nutrition laboratory in Pune and provided training to the community health workers (CHW) for keeping various types of qualitative and quantitative records related to the intervention. The technician was responsible for collecting the blood samples from the women.

\section{Developing Fe-rich recipes from green leafy vegetables}

Several points were considered in developing and standardising the Fe-rich recipes. First, emphasis was given to using locally available, low-cost ingredients in developing the recipes. Second, along with $\mathrm{Fe}$, an attempt was made to increase the content of other important micronutrients like folic acid, vitamin $\mathrm{C}, \beta$-carotene and $\mathrm{Ca}$, which are known to promote fetal growth. Third, it was essential to ensure that the recipes were easy to prepare, less time consuming and palatable, and could provide a variety of options for substitution. Finally, it was necessary that these recipes were not new dishes but were developed by incorporating GLV into the women's staple foods like roti, dhal, etc. for increasing their Fe intake substantially.

\section{Salient features of Fe-rich recipes}

The habitual diet of the women consisted of a roti (wheat or sorghum bread), a pulse or legume or vegetable curry, green chilli chutney and rice. It lacked salad, curd or buttermilk and GLV, and thus lacked variety. The recipes developed were essentially modifications of 
the commonly consumed recipes in rural areas. Thus, roti - a major food in their diet - was modified to spicy roti (thalipith/paratha) with the addition of GLV in the dough. Similarly, rice was modified with spring onion and cabbage leaves. Dhal preparation, another integral part of the diet, was developed with GLV and in informal meetings use of lemon in dhal during meals was recommended for increasing Fe absorption.

Among the side dishes, dry besan (pithale, made from gram flour) was most frequently consumed in all rural families. Addition of GLV to it thus ensured increased protein intake as well as increased frequency of GLV consumption. Green chilli chutney, which was part and parcel of their daily diet, was enriched with micronutrients by adding lot of coriander or mint and lemon. Salad was never a part of the rural diet but was developed for its maximum benefit (nutrient security), as losses of vitamins due to cooking are totally prevented. Use of lemon juice in its dressing was insisted upon to increase Fe bioavailability.

GLV soup was not only rich in vitamins but also had a texture suitable for young and old alike. Vegetable rolls (mutkule or tikki) developed using fenugreek or spinach was never known to rural women and became a popular dish.

Recipes were developed from thirteen commonly consumed GLV in this community, such as amaranth, spring onion (onion stalk), shepu, chakwat (bathua leaves), kardai (safflower leaves), mula (radish leaves), spinach, fenugreek leaves, ambat chukka, etc., used singly or in combinations to maximise Fe content.

\section{Community bealtb workers}

Young married girls from the local community, who had schooling up to 10th standard and a good rapport with rural women, were appointed as $\mathrm{CHW}$ for each village. Duties of the CHW involved motivating women for attending meetings and for giving blood samples, visiting each women a couple of times in a week to inform about the date and time of meetings, keeping attendance records of the meetings, distributing the blood reports, and occasionally accompanying the technician on house visits for collecting a blood sample from women not attending the meetings. They maintained the record of women attending the meetings and also of women who were actually doing the recipes in their homes, during their weekly visits. Finally, they also repeated the demonstrations of the recipes to small groups of five to ten women, especially for those who could not come for the regular meetings.

\section{Intervention}

Although the major intervention was developing Fe-rich recipes from commonly consumed GLV and organising their live demonstration regularly, this was facilitated through informal meetings organised once per month. All women were initially given a deworming tablet under medical supervision. Health-related issues such as symptoms and adverse effects of anaemia during pregnancy, increased requirements during pregnancy, importance of macro- and micronutrients in relation to birth size and anaemia, etc. were discussed in the local dialect by a lady doctor during the meetings. Similarly, the nutritionist discussed the sources of micronutrients, the benefits of eating raw salads, the importance of seasonal fruits like guava, tamrind and zizapus which are rich sources of vitamin C, etc. A poster in the size of a calendar, showing pictures and messages in the local language related to causal factors, symptoms and implications of anaemia, was prepared and given to each enrolled woman.

\section{Live demonstrations of Fe-rich recipes from green leafy vegetables}

In the beginning, the nutritionist explained the importance of the different ingredients used in the recipes to be demonstrated and also the possible substitutes for these ingredients. During each meeting, three or four recipes from a particular GLV were demonstrated. After the demonstration all women were then given a sample of these recipes prepared, along with a roti, for actual tasting of the recipes demonstrated. The activity of live demonstrations of recipes became popular as cooking is dear to rural women and it made a significant impact as 'seeing is believing'. At the end, each woman was given (free of cost) a bunch of the GLV so that they would repeat at least one of the recipes demonstrated for their evening meal. The description of the recipe in a local dialect was prepared and copies were distributed immediately. Additional copies were kept with $\mathrm{CHW}$ so that women who could not attend the meeting would get it from CHW. Similarly, a poster in the form of a wall calendar, summarising various types of recipes that can be prepared from GLV, was prepared with colourful pictures of the recipes and distributed to all women in the study. In total fifty Fe-rich recipes using commonly consumed GLV were demonstrated and demonstrations were repeated by $\mathrm{CHW}$ in small groups of women.

As per the cut-off for $\mathrm{Hb}$ in the government programme, Fe tablets ( $60 \mathrm{mg}$ of elemental $\mathrm{Fe}$ ) were given to women with $\mathrm{Hb}<11 \mathrm{~g} / \mathrm{dl}$, who formed the supplemented group; while those with $\mathrm{Hb}>11 \mathrm{~g} / \mathrm{dl}$ formed the nonsupplemented group. However, the analysis was done separately for supplemented and non-supplemented groups for examining the impact of the intervention involving dietary diversification.

\section{Monitoring interventional activities}

Two important aspects of the intervention were attending the meeting for gaining nutrition- and health-related knowledge especially focused on pregnancy and learning the Fe-rich recipes from live demonstrations. A separate notebook was maintained with $\mathrm{CHW}$ for keeping records 
of the interventional activities. For each meeting they recorded the names of the women attending the meeting. The second important aspect was to know whether the women were repeating the recipes at home. The CHW visited each woman weekly; to facilitate this, the total eligible women in a village were divided into six groups and each group was visited on a fixed day of the week from Monday to Saturday, thus covering the entire sample in a week's time. During their weekly visits, $\mathrm{CHW}$ recorded which recipes out of those demonstrated were actually done in the week following the meeting by each enrolled woman.

\section{Statistical metbods}

Differences in mean gain in $\mathrm{Hb}$ between the initial and final rounds (after 1 year) were tested using the paired $t$ test. Linearity of trend in mean gain in $\mathrm{Hb}$ by interventional activity group was tested using one-way ANOVA. The proportions of women with Fe-deficiency anaemia in various categories of nutritional status (using anthropometric measurements) were tested for trend using the $Z$ test. Multiple logistic regression analysis was carried out for computing odds ratios for risk of no gain in $\mathrm{Hb}$ associated with various factors. All analyses were conducted using the statistical software package SPSS/PC + for Windows version $11 \cdot 0$. Ethical permission was obtained from Agharkar Research Institute Ethical Committee for Human Studies before implementing the project.

\section{Results}

\section{Distribution of $\mathrm{Hb}$ and prevalence of anaemia}

Distribution of $\mathrm{Hb}$ in the initial and final rounds for nonpregnant women of childbearing age is shown in Fig. 1. The shift of the $\mathrm{Hb}$ distribution to the right after 1 year clearly indicates improvement in the $\mathrm{Hb}$ status of women. The prevalence of severe anaemia $(\mathrm{Hb}<10 \mathrm{~g} / \mathrm{dl})$ reduced significantly $(P<0 \cdot 001)$ from $19 \cdot 2 \%$ in the initial year to $7 \cdot 1 \%$ at the end of 1 year. There was also a significant $(P<0.001)$ rise from $18.0 \%$ to $44.6 \%$ in the proportion of women with normal $(>12 \mathrm{~g} / \mathrm{dl}) \mathrm{Hb}$ levels. The prevalence of anaemia was thus reduced significantly $(P<0 \cdot 01)$ at the end of the first year (from $82 \cdot 0 \%$ to $55 \cdot 4 \%$ ) and the same was also true for the prevalence of Fe-deficiency anaemia, which decreased from $30 \cdot 3 \%$ in the initial year to $10 \cdot 8 \%$ at the end of 1 year $(P<0 \cdot 01)$. Overall gain in $\mathrm{Hb}$ over the period of 1 year for the entire group was $0.66 \mathrm{~g} / \mathrm{dl}$ (Table 1). Women who were given Fe tablets showed a significant $(P<0.001)$ improvement in $\mathrm{Hb}(1.36 \mathrm{~g} / \mathrm{dl})$, while in the non-supplemented group improvement in $\mathrm{Hb}$ $(0 \cdot 18 \mathrm{~g} / \mathrm{dl})$ was marginally significant $(P=0 \cdot 06)$.

The improvement in mean $\mathrm{Hb}$ was inversely associated with the initial level of $\mathrm{Hb}$, showing the highest gain of $2 \cdot 0$ (SD $1 \cdot 66$ ) $\mathrm{g} / \mathrm{dl}$ among women with $\mathrm{Hb}$ below $9 \cdot 0 \mathrm{~g} / \mathrm{dl}$ (Fig. 2). Furthermore, Hb gain was examined by various

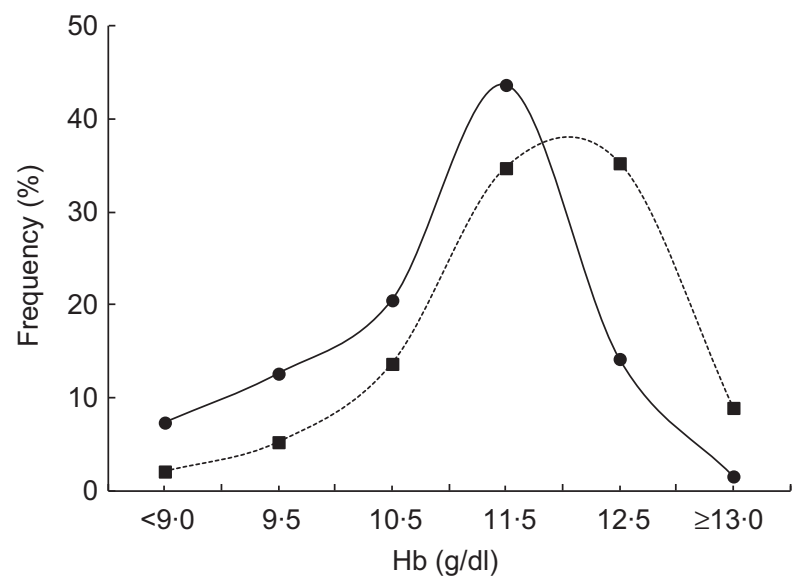

Fig. $1 \mathrm{Hb}$ distribution in the initial year (-0-) and after 1 year (- - - -) of the intervention to modify dietary habits for the prevention of anaemia among rural, non-pregnant women ( $n$ 240) of childbearing age (15-35 years) from three villages near Pune city, Maharashtra, India

Table 1 Mean $\mathrm{Hb}(\mathrm{g} / \mathrm{dl})$ at the initial and final rounds and gain in $\mathrm{Hb}(\mathrm{g} / \mathrm{dl})$, according to supplementation group, among rural, nonpregnant women ( $n$ 190) of childbearing age (15-35 years) from three villages near Pune city, Maharashtra, India

\begin{tabular}{|c|c|c|c|c|c|c|c|}
\hline \multirow[b]{2}{*}{ Group } & \multirow[b]{2}{*}{$n$} & \multicolumn{2}{|c|}{$\begin{array}{c}\text { Initial Hb } \\
\text { (g/dl) }\end{array}$} & \multicolumn{2}{|c|}{$\begin{array}{c}\text { Final Hb } \\
(\mathrm{g} / \mathrm{dl})\end{array}$} & \multicolumn{2}{|c|}{$\begin{array}{l}\text { Gain } \\
\text { (g/dl) }\end{array}$} \\
\hline & & Mean & SD & Mean & SD & Mean & SD \\
\hline Supplemented & 77 & $9 \cdot 80$ & $1 \cdot 02$ & $11 \cdot 16$ & $1 \cdot 32$ & $1 \cdot 36$ & $1 \cdot 28$ \\
\hline Non-supplemented & 113 & $11 \cdot 71$ & 0.55 & $11 \cdot 89$ & $0 \cdot 83$ & $0 \cdot 18$ & 0.98 \\
\hline All & 190 & $10 \cdot 94$ & $1 \cdot 22$ & $11 \cdot 59$ & $1 \cdot 11$ & $0 \cdot 66$ & $1 \cdot 26$ \\
\hline
\end{tabular}

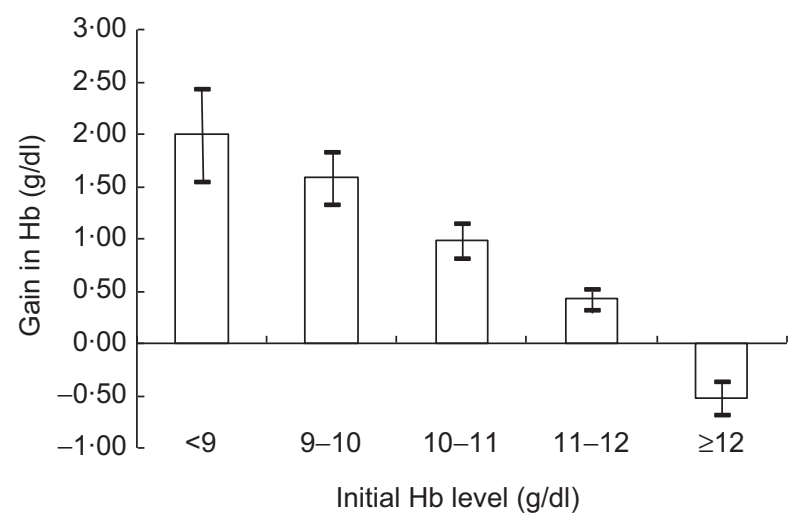

Fig. 2 Gain in $\mathrm{Hb}(\mathrm{g} / \mathrm{dl})$ after 1 year of the intervention, according to initial $\mathrm{Hb}$ level, among rural, non-pregnant women ( $n$ 190) of childbearing age (15-35 years) from three villages near Pune city, Maharashtra, India. Values are means with their standard errors represented by vertical bars

maternal characteristics (Table 2). Gain in mean $\mathrm{Hb}$ was significant $(P<0 \cdot 001)$ in all categories of pre-pregnant weight but appeared to be higher in the lowest weight category and decreased with increase in maternal weight. 
Table $2 \mathrm{Mean} \mathrm{Hb}(\mathrm{g} / \mathrm{dl})$ in the initial and final rounds and gain in $\mathrm{Hb}(\mathrm{g} / \mathrm{dl})$, according to various maternal characteristics, among rural, non-pregnant women $(n 190)$ of childbearing age (15-35 years) from three villages near Pune city, Maharashtra, India

\begin{tabular}{|c|c|c|c|c|c|c|c|}
\hline \multirow[b]{3}{*}{ Maternal characteristic } & \multirow[b]{3}{*}{$n$} & \multicolumn{6}{|c|}{$\mathrm{Hb}(\mathrm{g} / \mathrm{dl})$} \\
\hline & & \multicolumn{2}{|c|}{ Initial } & \multicolumn{2}{|c|}{ Final } & \multicolumn{2}{|c|}{ Gain } \\
\hline & & Mean & SD & Mean & SD & Mean & SD \\
\hline \multicolumn{8}{|l|}{ Pre-pregnant weight $(\mathrm{kg})$} \\
\hline$<40$ & 33 & $10 \cdot 69$ & $1 \cdot 26$ & $11 \cdot 57$ & $1 \cdot 46$ & $0 \cdot 87^{*}$ & $1 \cdot 32$ \\
\hline $40-50$ & 118 & $10 \cdot 94$ & $1 \cdot 23$ & 11.57 & $1 \cdot 07$ & $0.63^{*}$ & $1 \cdot 24$ \\
\hline$\geq 50$ & 38 & $11 \cdot 13$ & $1 \cdot 12$ & $11 \cdot 67$ & 0.94 & $0.53^{*}$ & $1 \cdot 24$ \\
\hline \multicolumn{8}{|c|}{ Pre-pregnant BMI $\left(\mathrm{kg} / \mathrm{m}^{2}\right)$} \\
\hline$<18.5$ & 71 & $10 \cdot 96$ & $1 \cdot 21$ & $11 \cdot 53$ & $1 \cdot 30$ & $0.57^{*}$ & $1 \cdot 21$ \\
\hline $18 \cdot 5-20 \cdot 0$ & 53 & $10 \cdot 69$ & $1 \cdot 20$ & $11 \cdot 44$ & $1 \cdot 14$ & $0 \cdot 75^{\star}$ & $1 \cdot 27$ \\
\hline$\geq 20 \cdot 0$ & 65 & $11 \cdot 12$ & $1 \cdot 22$ & $11 \cdot 77$ & 0.83 & $0 \cdot 65^{\star}$ & $1 \cdot 30$ \\
\hline \multicolumn{8}{|l|}{ Height $(\mathrm{cm})$} \\
\hline$<150$ & 48 & $10 \cdot 73$ & $1 \cdot 34$ & $11 \cdot 52$ & 0.99 & $0.79^{*}$ & 1.49 \\
\hline $150-155$ & 72 & $11 \cdot 06$ & $1 \cdot 19$ & $11 \cdot 60$ & $1 \cdot 23$ & $0.54^{*}$ & $1 \cdot 04$ \\
\hline$\geq 155$ & 70 & $10 \cdot 95$ & $1 \cdot 15$ & $11 \cdot 64$ & 1.08 & $0.68^{*}$ & $1 \cdot 28$ \\
\hline \multicolumn{8}{|l|}{ Current age (years) } \\
\hline$<20$ & 52 & $11 \cdot 09$ & $1 \cdot 17$ & $11 \cdot 67$ & 0.88 & $0.58^{*}$ & $1 \cdot 23$ \\
\hline $20-25$ & 89 & $11 \cdot 06$ & 1.00 & $11 \cdot 65$ & $1 \cdot 07$ & $0.59^{*}$ & $1 \cdot 22$ \\
\hline$\geq 25$ & 46 & $10 \cdot 53$ & 1.54 & $11 \cdot 33$ & $1 \cdot 32$ & $0.81^{*}$ & 1.34 \\
\hline \multicolumn{8}{|l|}{ Parity } \\
\hline 0 & 58 & $11 \cdot 10$ & $1 \cdot 12$ & $11 \cdot 70$ & 0.94 & $0.60^{*}$ & $1 \cdot 22$ \\
\hline 1 & 70 & $11 \cdot 06$ & $1 \cdot 25$ & $11 \cdot 71$ & $1 \cdot 12$ & $0 \cdot 66^{*}$ & $1 \cdot 34$ \\
\hline$\geq 2$ & 59 & $10 \cdot 64$ & $1 \cdot 24$ & $11 \cdot 29$ & $1 \cdot 17$ & $0.65^{*}$ & $1 \cdot 19$ \\
\hline
\end{tabular}

${ }^{\star} P<0.01$ for gain in $\mathrm{Hb}$ over a period of 1 year using the paired $t$ test.

Table 3 Mean $\mathrm{Hb}(\mathrm{g} / \mathrm{dl})$ in the initial and final rounds and gain in $\mathrm{Hb}(\mathrm{g} / \mathrm{dl})$, according to participation in various social actions and supplementation group, among rural, non-pregnant women ( $n$ 190) of childbearing age (15-35 years) from three villages near Pune city, Maharashtra, India

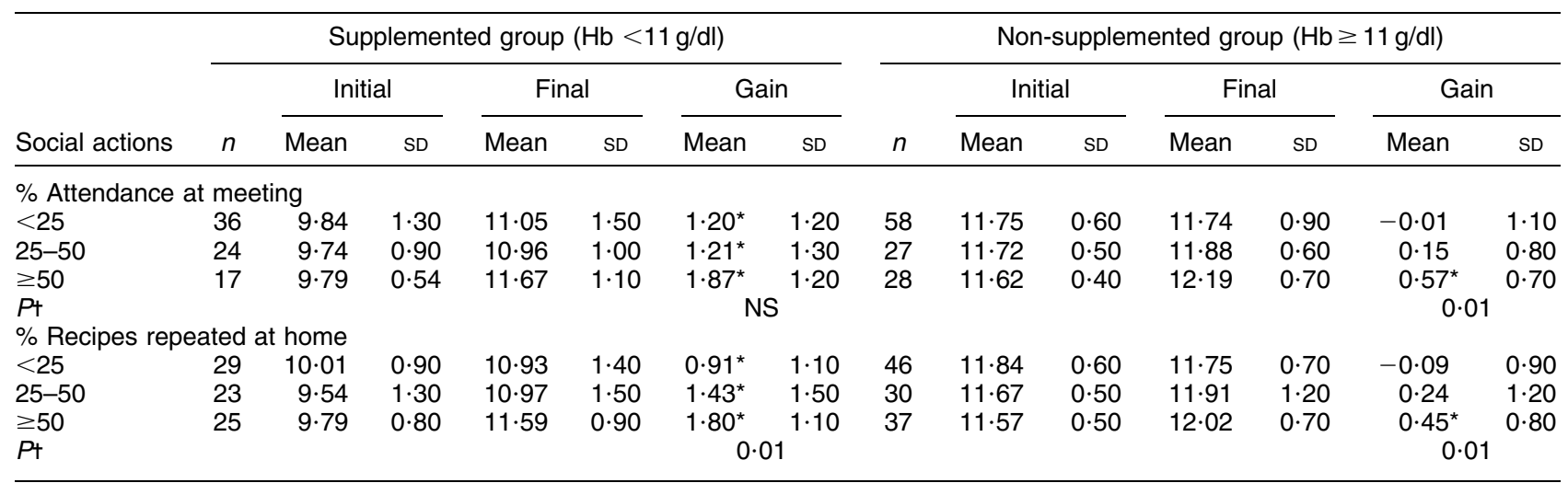

${ }^{\star} P<0.01$ for gain in $\mathrm{Hb}$ over a period of 1 year using the paired $t$ test.

thinearity of trend in mean gain in $\mathrm{Hb}$ using one-way ANOVA.

Similarly, gain in mean $\mathrm{Hb}$ was highest in short mothers $(<150 \mathrm{~cm})$, among those who had high parity $(>1)$ and among older mothers ( $>25$ years), indicating greater benefits to the undernourished mothers.

\section{Impact of the intervention on Hb status}

In order to examine the effect of the intervention, supplemented and non-supplemented groups are considered separately. Informal meetings preceded the live demonstrations for discussion of Fe-rich recipes by the nutritionist. Women were classified by their participation levels in attending these meetings. It was equally important to repeat these recipes at home frequently. It can be seen (Table 3) that in the supplemented group, even with the lowest level of participation $(<25 \%$ attendance) in informal meetings, the gain in $\mathrm{Hb}$ was $1.20 \mathrm{~g} / \mathrm{dl}$ but increased to $1.87 \mathrm{~g} / \mathrm{dl}$ in the case of women having higher participation ( $>50 \%$ attendance), indicating the benefits of participation. In the non-supplemented group, although the magnitude of gain was much smaller, an increasing trend $(P<0 \cdot 01)$ in $\mathrm{Hb}$ gain was seen with increasing attendance indicating the effect of this interventional activity. In particular, women attending more than $50 \%$ of the meetings in the non-supplemented group 
showed significant gain in $\mathrm{Hb}(0.57 \mathrm{~g} / \mathrm{dl})$ that was about one-third of the gain observed in the supplemented group.

With regard to the main intervention in the study, repeating the demonstrated recipes at home was essential. It can be seen (Table 3) that not only was the gain in $\mathrm{Hb}$ significant for all levels of participation, but it also showed a significant $(P<0 \cdot 01)$ increasing trend with the increase in level of participation. Thus supplemented women who repeated more than $50 \%$ of the recipes at home showed almost double the gain in $\mathrm{Hb}(1.80 \mathrm{~g} / \mathrm{dl})$ compared with those who could repeat only less than $25 \%$ of the recipes $(0.91 \mathrm{~g} / \mathrm{dl})$. Once again among the non-supplemented group, although the magnitude of the gain was low, an increasing trend $(P<0.01)$ in $\mathrm{Hb}$ gain was seen with increasing participation. In particular, the gain in $\mathrm{Hb}$ $(0 \cdot 45 \mathrm{~g} / \mathrm{dl})$ among non-supplemented women having the highest participation in this activity was about $25 \%$ of that observed in the supplemented group. Thus, in the non-supplemented group, the magnitude of gain in $\mathrm{Hb}$ was significant only for the highest level of participation and showed an independent effect.

\section{Effect of the intervention on consumption of green leafy vegetables}

Data from the FFQ were analysed to see whether the interventional activities had an impact on actual consumption of micronutrient-rich foods, especially GLV and seasonally available fruits. It can be seen (Fig. 3) that the frequency of GLV consumption less than once weekly decreased from $19 \cdot 7 \%$ to $5 \cdot 6 \%$, while that of GLV consumption more than twice weekly increased substantially from $44.7 \%$ to $60 \cdot 6 \%$ during the period of 1 year in the supplemented group. Similar trends were also seen in the non-supplemented group. A significant change was also observed in the consumption of locally available seasonal fruits during the period of 1 year, in both supplemented and non-supplemented groups (Fig. 3). Thus the observations show that the intervention undertaken in the present study improved the actual consumption of GLV and fruits which provide not only Fe but combinations of micronutrients, resulting in the improved $\mathrm{Hb}$ status of the study women.

Multiple logistic regression analysis was done to examine the risk of no improvement in $\mathrm{Hb}$ over a period of 1 year and to observe the odds for various confounding factors (Table 4). Among all maternal parameters (weight, height, parity and age) considered, only in the case of maternal age was the risk of no improvement in $\mathrm{Hb}$ seen to be marginally significant $(P=0 \cdot 06)$. However, both meeting attendance $(P=0.04)$ and repeating at home the recipes demonstrated in the meetings $(P=0 \cdot 03)$ showed significant associations with gain in $\mathrm{Hb}$. Women with lower attendance at meetings $(<50 \%)$ as well as those repeating recipes at home less frequently $(<50 \%)$ showed about three times higher risk for no gain in $\mathrm{Hb}$ compared with their counterparts with higher attendance ( $\geq 50 \%)$ or higher frequency of repeating recipes $(\geq 50 \%)$. Thus the
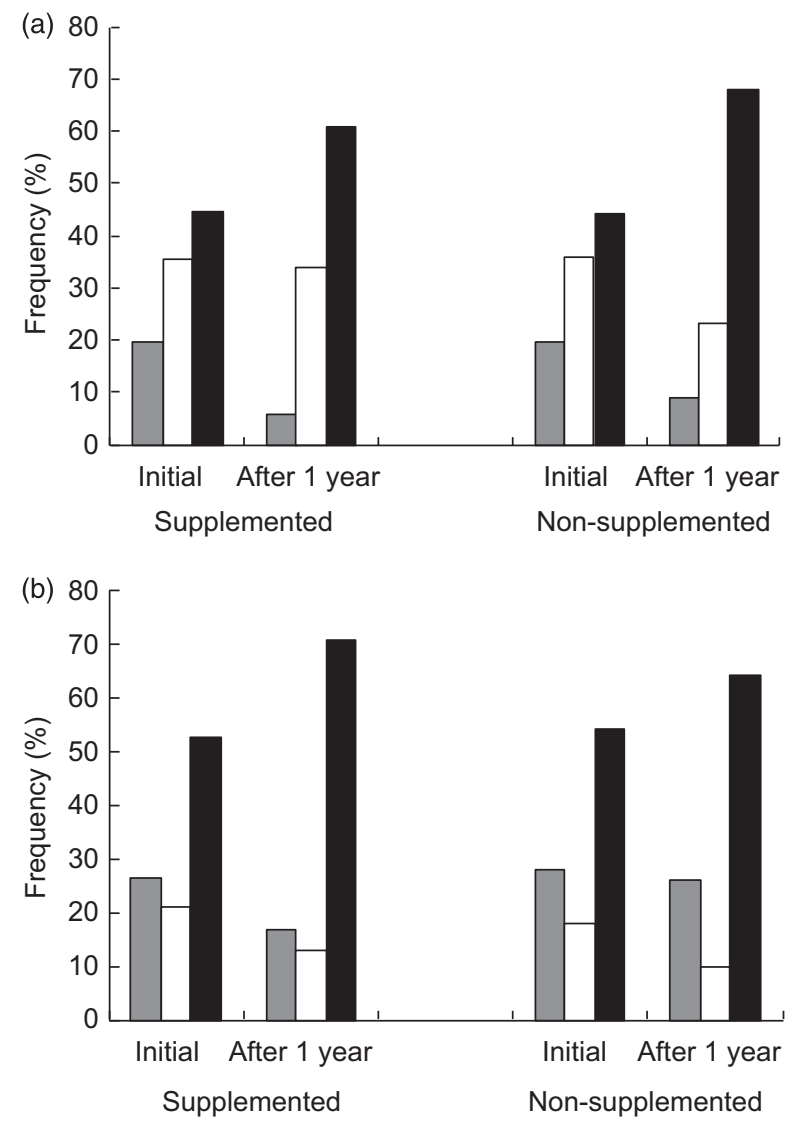

Fig. 3 Frequency of consumption ( $\square$, less than once weekly; $\square$, less than twice weekly; $\square$, more than twice weekly) of (a) green leafy vegetables and (b) fruits in the initial year and after 1 year of the intervention, according to supplementation group, among rural, non-pregnant women ( $n$ 190) of childbearing age (15-35 years) from three villages near Pune city, Maharashtra, India

interventional activities showed independent significant effects on $\mathrm{Hb}$. After adjusting for initial $\mathrm{Hb}$, the significance and the odds ratios increased in the case of social action parameters but disappeared in the case of maternal parameters, thus highlighting the importance of the interventional activities taken in the present study.

\section{Discussion}

Fe-deficiency anaemia resulting from inadequate intake and low absorption of dietary $\mathrm{Fe}$ is the most common form of anaemia in India ${ }^{(8,9)}$. The National Nutritional Anaemia Control Program distributes Fe + folic acid tablets to pregnant women but does not cover non-pregnant women of childbearing age. The existing programme has repeatedly been shown to be ineffective in reducing the prevalence of anaemia ${ }^{(3,4,18)}$, the reasons mentioned being poor access to prenatal care, insufficient and inconsistent supply of Fe supplements, insufficient counselling on the need for and the benefits of Fe supplements and, 
Table 4 Multiple logistic regression analysis for risk of no gain in $\mathrm{Hb}(\mathrm{g} / \mathrm{dl})$ among rural, non-pregnant women $(n 190)$ of childbearing age (15-35 years) from three villages near Pune city, Maharashtra, India

\begin{tabular}{|c|c|c|c|c|}
\hline Independent variable & Category & OR & $95 \% \mathrm{Cl}$ & $P$ \\
\hline \multirow[t]{2}{*}{ Pre-pregnant weight $(\mathrm{kg})$} & $<40$ & $1 \cdot 26$ & - & NS \\
\hline & $\geq 40$ & $1 \cdot 00$ & Ref. & \\
\hline \multirow[t]{2}{*}{ Height $(\mathrm{cm})$} & $<145$ & $0 \cdot 47$ & - & NS \\
\hline & $\geq 145$ & $1 \cdot 00$ & Ref. & \\
\hline \multirow[t]{2}{*}{ Parity } & $<2$ & $1 \cdot 10$ & - & NS \\
\hline & $\geq 2$ & $1 \cdot 00$ & Ref. & \\
\hline \multirow[t]{2}{*}{ Maternal age (years) } & $<22$ & $2 \cdot 27$ & $0.97,5.33$ & 0.06 \\
\hline & $\geq 22$ & $1 \cdot 00$ & Ref. & \\
\hline \multirow[t]{2}{*}{ Attendance at meetings $(\%)^{*}$} & $<50$ & 3.08 & $1 \cdot 04,9 \cdot 13$ & 0.04 \\
\hline & $\geq 50$ & $1 \cdot 00$ & Ref. & \\
\hline \multirow[t]{2}{*}{ Recipes repeated at home $(\%)^{*}$} & $<50$ & $2 \cdot 89$ & $1 \cdot 13,7 \cdot 41$ & 0.03 \\
\hline & $\geq 50$ & $1 \cdot 00$ & Ref. & \\
\hline \multirow[t]{2}{*}{ Frequency of GLV consumption* } & $<$ Twice weekly & 0.51 & - & NS \\
\hline & $\geq$ Twice weekly & 1.00 & Ref. & \\
\hline \multirow[t]{2}{*}{ Frequency of fruit consumption* } & $<$ Twice weekly & 0.97 & - & NS \\
\hline & $\geq$ Twice weekly & $1 \cdot 00$ & Ref. & \\
\hline
\end{tabular}

GLV, green leafy vegetables; Ref., referent category.

*Entered as a grouped variable.

more importantly, an unwillingness by pregnant women to take $\mathrm{Fe}$ supplements ${ }^{(19)}$. As Fe deficiency is likely to be compounded by multiple micronutrient deficiencies, simultaneous efforts for increasing the consumption of micronutrient-rich vegetarian foods are also essential. Clearly, GLV form a food group of potential interest as they are a rich and cheap source of all vitamins and minerals, but more research is urgently needed for investigating the effects of dietary diversification in poor populations. Our study shows that addressing rural women through social actions, namely live demonstration of Fe-rich recipes for imparting nutritional knowledge and awareness, was able to reduce the prevalence of anaemia significantly.

Anaemia prevalence in the young, rural, non-pregnant women of childbearing age in our study was as large as $82 \%$ and is in agreement with the prevalence of anaemia reported by studies from different states in India ${ }^{(20,21)}$. Despite this we found that the prevalence of Fe-deficiency anaemia was only $30 \cdot 3 \%$, which indicates that other causes of anaemia may be prevalent in this population. Similar observations are reported in the case of Nepali women ${ }^{(22)}$. Hookworm infection and malaria are endemic in this population and region, and the majority of women may in fact have worm infestation. The larger the prevalence of anaemia, the more likely it is to have multiple causes and not be related solely to Fe deficiency. Although ferritin is commonly considered for detecting Fe deficiency, it is reported that there may be normal serum ferritin values despite a true Fe deficiency. In contrast, red-blood-cell morphology clearly revealed that Fe deficiency was largely confined to $\mathrm{Hb}$ levels below $11 \mathrm{~g} / \mathrm{dl}$, as $75 \%$ of women with $\mathrm{Hb}$ below this level had Fe-deficiency anaemia. Thus red-blood-cell morphology, although not a robust method, is certainly a simple and cost-effective tool for identifying Fe-deficiency anaemia compared with other biochemical indicators.
At the end of 1 year the distribution of Hb showed a clear shift to the right when compared with the initial distribution and showed a significant reduction in the prevalence of anaemia. The gain in $\mathrm{Hb}$ was highest among women with low initial $\mathrm{Hb}(<9 \mathrm{~g} / \mathrm{dl})$ or who were undernourished. It is known that severely Fe-deficient individuals are more efficient in absorbing $\mathrm{Fe}$ and hence would derive more benefit than less Fe-deficient individuals ${ }^{(11)}$.

Although there is much evidence supporting the use of Fe supplementation in vulnerable groups, findings on the effects of nutrition education without supplementation and/or food fortification are lacking ${ }^{(15)}$. Nevertheless, the limited evidence available highlights potential benefits associated with nutrition education as an intervention for improving $\mathrm{Fe}$ status in Indian ${ }^{(23,24)}$ and other populations ${ }^{(25,26)}$. In fact, our approach of nutrition education was around a social action of live demonstration of Fe-rich recipes. We observed that the higher $(>50 \%)$ the participation in the interventional activities, the higher was the gain in $\mathrm{Hb}$. Further, when education is transformed into action the benefits are likely to be more. Thus, women who repeated only $25-50 \%$ of the recipes shown to them exhibited a greater gain in $\mathrm{Hb}(1.43 \mathrm{~g} / \mathrm{dl})$ than those who attended $25-50 \%$ of the meetings $(1 \cdot 21 \mathrm{~g} / \mathrm{dl})$.

Dietary interventions have always resulted in relatively smaller change in $\mathrm{Hb}$ compared with Fe supplementation $^{(27)}$. In our study too, improvement in $\mathrm{Hb}$ in the nonsupplemented group was of smaller magnitude and was seen only in the highest level of participation compared with that in the group supplemented with Fe tablets. But this was not surprising as our intervention was addressing only behavioural change to improve the women's dietary status with regard to Fe. In fact, the small but significant improvements in the non-supplemented group assure that the intervention has effectively improved their knowledge with regard to consumption of GLV, which was also 
confirmed through food frequency data. Increase in the consumption of greens through nutrition education intervention has also been reported among women from Mysore $^{(28)}$. We observed that the intervention undertaken in the present study improved the actual consumption of GLV and fruits significantly in both the supplemented and non-supplemented group. In particular, the proportion of women consuming GLV more than twice weekly increased from $36 \%$ to $76 \%$ among those attending meetings and those repeating the recipes at home more frequently, highlighting the impact of our intervention. The implication is that this will not only provide Fe but also combinations of micronutrients, resulting in the improved $\mathrm{Hb}$ status of the women in the study.

Finally, even after adjusting for other confounders, the multiple logistic regression analysis revealed the odds associated with no gain in $\mathrm{Hb}$ to be almost three times higher for women with low participation compared with those having high participation, thus emphasising the need for health education programmes for dietary diversification. It is believed that a lack of knowledge of the causes and consequences of nutritional deficiencies may influence food choices even in resource-poor populations ${ }^{(29)}$. Therefore, education to change knowledge, attitudes and household dietary practices may be required to effect positive changes in consumption and nutritional status. Food-based approaches to combat deficiencies of micronutrients deserve great attention because they are likely to be sustainable in the long term and will facilitate simultaneous increase in intake of all the micronutrients.

It is worthwhile to mention that the interventional activities offered several social impacts. First, the women learned many recipes and were certainly appreciated at home for offering variety in the diet. Second, although we measured $\mathrm{Hb}$ of women enrolled in the study, other family members must have benefited from the increased consumption of GLV owing to our intervention. Finally, the impact at the community level was that the village heads and multipurpose workers from neighbouring villages often attended the live demonstration meetings, thus spreading nutritional knowledge and awareness related to anaemia beyond the project villages.

\section{Conclusion}

Our observations indicate that the massive problem of anaemia in rural India, where ignorance is one of the root causes of the disease, needs education to change knowledge, attitudes and household dietary practices. Although technical solutions like fortification are possible for reducing Fe-deficiency anaemia at the population level, our study underscores the fact that nutrition education around social actions leading to dietary modification will bring about behavioural change resulting in sustainable improvement in the overall quality of the diet. It thus provides a feasible opportunity to attain high-priority health goals. Second, efforts to generate nutritional awareness through kitchen garden activity or arranging food exhibitions etc. may also be helpful. In Indonesia, social marketing played a critical role in increasing the consumption of vitamin A from plant and animal sources ${ }^{(13)}$. It is beyond doubt that not only operational research on how best to improve the existing Fe supplementation programme is needed ${ }^{(30)}$, but also new and innovative strategies are required to improve the overall health and nutritional status of young rural mothers in India.

\section{Acknowledgements}

Sources of funding: The work was supported by the Science and Society Division, Department of Science and Technology, New Delhi. Conflicts of interest: The authors have no conflicts of interest. Authors' contributions: S.R. was the Principal Investigator and was responsible for planning of the study, interpreting the results and writing the manuscript. S.J. was responsible for execution and supervision of the data collection and also statistical analysis of the data. P.B. and B.P. were responsible for developing Fe-rich recipes and were responsible for live demonstrations in the field. K.A. participated in statistical analysis of the data. Acknowledgements: The authors wish to thank the funders for providing funds to carry out the research. They also thank all of the rural mothers who participated in the study.

\section{References}

1. Administrative Committee on Coordination/Subcommittee on Nutrition (1991) Controlling Iron Deficiency. ACC/SCN State of the Art Series, Nutrition Policy Discussion Paper no. 9. Geneva: ACC/SCN.

2. Seshadri S, Sharma K, Ra AE et al. (1994) Iron supplementation to control pregnancy anaemia. Proc Nutr Soc India 41, 131-140.

3. Sood SK, Ramachandran K, Mathur M et al. (1975) WHO sponsored collaborative studies on nutritional anaemia in India. 1. The effects of supplemental oral iron administration to pregnant women. Q J Med $\mathbf{4 4}$, 241-258.

4. ICMR Task Force Study (1989) Evaluation of the National Nutritional Anaemia Prophylaxis Programme. New Delhi: Indian Council of Medical Research.

5. ICMR Task Force Study (1992) Field Supplementation Trials in Pregnant Women with $60 \mathrm{mg}, 120 \mathrm{mg}$ and $180 \mathrm{mg}$ of Iron with $500 \mathrm{mcg}$ of Folic Acid. New Delhi: Indian Council of Medical Research.

6. Christian P, Abbi R, Gujral S et al. (1989) At risk status of pregnant women of Panchmahals (Gujarat) and Ghandrapur (Maharashtra). Arogya J Health Sci 15, 85-91.

7. Agarwal DK, Agarwal KN \& Tripathi AM (1987) Nutritional status in rural pregnant women of Bihar and Uttar Pradesh. Indian Pediatr 24, 119-125.

8. Sarin AR (1995) Severe anaemia of pregnancy: recent experience. J Gynaecol Obstet 50, Suppl. 27, 545-549. 
9. Toteja GS \& Singh P (2004) Micronutrient Profile of Indian Population. New Delhi: Indian Council of Medical Research.

10. Rao BSN (1978) Studies on iron deficiency anaemia. Indian J Med Res Suppl. 68, 58-69.

11. Beard JL (2000) Effectiveness and strategies of iron supplementation during pregnancy. Am J Clin Nutr 71, 5 Suppl., 1288S-1294S.

12. Backstrand JR, Allen LH, Black AK et al. (2002) Diet and iron status of nonpregnant women in rural Mexico. Am J Clin Nutr 76, 156-164.

13. De Pee S, Bloem MW, Satoto et al. (1998) Impact of social marketing campaign promoting dark green leafy vegetables and eggs in Central Java, Indonesia. Int J Vitam Nutr Res 68, 389-398.

14. Ahmed F, Khan MR, Akhtaruzzaman M et al. (2005) Efficacy of twice weekly multiple micronutrient supplementation for improving the hemoglobin and micronutrient status of anemic adolescent school girls in Bangladesh. Am J Clin Nutr 82, 829-835.

15. Amani R \& Soflaei M (2006) Nutrition education alone improves dietary practices but not hematologic indices of adolescent girls in Iran. Food Nutr Bull 27, 260-264.

16. Rao S, Yajnik CS, Kanade A et al. (2001) Intake of micronutrient rich foods in rural Indian mothers is associated with the size of their babies at birth: Pune maternal nutrition study. J Nutr 131, 1217-1224.

17. Dacie JV \& Lewis SM (2006) Practical Haematology, 10th ed. Edinburgh: Churchill Livingstone.

18. Ramachandran P (1989) Nutrition in pregnancy. In Women and Nutrition in India, pp. 153-193 [C Gopalan and S Kaur, editors]. New Delhi: Nutrition Foundation of India Special Publication Services.

19. Bothwell TH (2000) Iron requirements in pregnancy and strategies to meet them. Am J Clin Nutr 72, 1 Suppl., 257S-264S.

20. Saibaba A, Mohan Ram M, Ramana Rao GV et al. (2002) Nutritional status of adolescent girls of urban slums and the impact of IEC on their nutritional knowledge and practices. Indian J Community Med 27, 151-156.

21. Kaur S, Deshmukh PR \& Garg BS (2006) Epidemiological correlates of nutritional anaemia in adolescent girls of rural Wardha. Indian J Community Med 31, 255-258.

22. Chandyo RK, Strand TA, Ulvik RJ et al. (2007) Prevalence of iron deficiency and anemia among healthy women of reproductive age in Bhaktapur, Nepal. Eur J Clin Nutr 61, 262-269.

23. Kapur D, Sharma S \& Agarwal KN (2003) Effectiveness of nutrition education, iron supplementation or both on iron status in children. Indian Pediatr 40, 1131-1144.

24. Garg A \& Kashyap S (2006) Effect of counseling on nutritional status during pregnancy. Indian J Pediatr $\mathbf{7 3}$, 687-692.

25. Kafatos AG, Vlachonikolis IG \& Codrington CA (1989) Nutrition during pregnancy: the effects of an educational intervention program in Greece. Am J Clin Nutr 50, 970-979.

26. Creed-Kanashiro HM, Bartolini RM, Fukumoto MN et al. (2003) Formative research to develop a nutrition education intervention to improve dietary iron intake among women and adolescent girls through community kitchens in Lima, Peru. J Nutr 133, 11 Suppl. 2, 3987S-3991S.

27. Patterson AJ, Brown WJ, Roberts DCK et al. (2001) Dietary treatment of iron deficiency in women of childbearing age. Am J Clin Nutr 74, 650-656.

28. Hemalatha MS \& Prakash J (2002) An awareness creation programme for women on nutrition through green leafy vegetables. Indian J Nutr Diet 39, 17-25.

29. Jones KM, Specio SE, Shrestha P et al. (2005) Nutrition knowledge and practices and consumption of vitamin A-rich plants by rural Nepali participants and nonparticipants in a kitchen-garden program. Food Nutr Bull 26, 198-208.

30. Bentley ME \& Griffiths PL (2003) The burden of anemia among women in India. Eur J Clin Nutr 57, 52-60. 